\title{
A New Genus and New Species of Acarid Mites (Acari: Acaridae) from Soil Under Pomegranate Trees, at Assiut, Upper Egypt
}

\author{
Sayed A. Eraky*, Nazeh M. Abd El-Wahed ${ }^{* *}$, Abdelgayed S. Abdelgayed ${ }^{* *}$ \\ and Abd El-Wahab M. Ali*, \\ *Dept. of Plant Protec., Fac. of Agric., Assiut Univ., Assiut, 71526, Egypt, seraky53@yahoo.com. \\ ${ }^{* *}$ Plant Protec. Res. Inst., Agric. Res. Center, Dokkii, 12611, Giza, Egypt.
}

\begin{abstract}
A new genus (Egyptglyphus gen. nov.) and new species (Egyptglyphus oconnori sp. nov.) is described from hypopial nymphs (heteromorphic deutonymphs), collected from soil under pomegranate trees, Assiut Governorate, Egypt. Holotype deutonymph and seven paratype deutonymphs are deposited in the Acari collection of Plant Protection Department, Faculty of Agriculture, Assiut University, Assiut Governorate, Egypt. The characterization and description of the new genus and species are given.
\end{abstract}

Key words: Acarina; Egyptglyphus; taxonomy; description; deutonymph; Egypt.

\section{INTRODUCTION}

The acaroids mites are economically and veterinary important mite pests exploiting a wide range of patchy habitats. They can be found in nests of vertebrates (mammals and birds) and invertebrates (ants, termites, beetles, wasps and bees), decomposing organic matter (animal manure and dung-hills, various plant materials), a few species are aquatic or parasitic on gills of fresh-water crabs. While, others are serious pests of stored products, or as a common component of house dust mites. Some species belonging to the genera Acarus Linnaeus; Mycetoglyphus Oudemans; Tyrophagus Oudemans; Rhizoglyphus Claparédè and Caloglyphus Berlese (=Sancassania Oudemans) are pests on subterranean parts and young leaves of various crops and are serious agricultural pests causing injures to plants directly by feeding or indirectly by transmitting various disease agents (Diaz et al., 2000; Klimov and O'Connor, 2003; Fan and Zhang, 2004, 2007; Kasuga and Amano, 2006; Rojas and Klimov, 2007; Klimov and Tolstikov, 2011). Others are constantly present in soil environment, use soil, arthropods and small mammals to disperse to patchy habitats. Dispersal between habitat patches is also affected by phoretic association between the specialized deutonymphs or even adults. Some species of the genera Tyrophagus, Rhizoglyphus, Schwiebea and Sancassania are common in both soil and patchy habitats. Most non-parasitic species had been described from either adults or dispersing deutonymphs, but some others had been described from both adults and deutonymphs (Fashing, 1974; Fain and Philips, 1978; Klimov, 2000). Many species of the family Acaridae were recorded in Upper Egypt by Eraky (1993, 1994, 1997, 1998, 1999a\&b, 2000); Eraky and Shoker (1993) and Eraky and Osman (2008). The study described a new genus and new species that showed sufficient dissimilarity with other described genera of the family Acaridae to be classified as a separate one.

\section{MATERIALS AND METHODS}

Mites were collected from soil under pomegranate at Assiut governorate, Upper Egypt. More than ten similar individuals of acarid deutonymphs (heteromorphic deutonymphs) were chosen. The collected deutonymphs were cleared up in lactic acid, mounted in Hoyer's medium on glass slides, dried in an oven at $50-55^{\circ} \mathrm{C}$, then examined under phase contrast (Optika-Vision-lite_ENG-rev01, Italy) research microscope, provided with camera and system of calibration of micrometric slide, a drawing tube was also used when necessary. The examination of the collected deutonymphs showed some interesting morphological characteristics which did not appear in the described genera of the family Acaridae. Measurements are given in micrometers $(\mu \mathrm{m})$, each measurement shows the average for a number of individuals, followed (in parentheses) by a respective range. The deutonymph of the new genera and species was described and illustrated. Nomenclature by Giffiths et al., 1990 was followed for idiosomal setae and Grandjean, 1939 for legs chaetotaxy. Holotype deutonymph and five paratype deutonymphs were measured for gnathosoma, idiosoma and idiosomal chatotaxy; holotype deutonymph was measured for legs and legs chaetotaxy.

\section{Egyptglyphus gen. nov.}

Diagnosis: (Hypopus). Gnathosoma elongate peculiar in shape, palps long, divided medially, palpal setae situated in the middle of palps, also for infracapitular setae. Idiosomal setae short, simple, except $h 2$, approximately long. Dorsum and internal parts of coxal fields I, II, III punctuate. Venter welldeveloped, but with unusual course of apodemes and ornamentation on coxal fields. Solenidia of legs I-IV have been modified or replaced by thin, whip-like setae (short or long), especially solenidia $\omega$ and $\varphi$ on both tarsi I and II. 
Type species: Egyptglyphus oconnori sp. nov.

Remarks: the new genus is mostly closed to the genera: Caloglyphus Berlese; Naiadacarus Fashing and Mycetosancassania Klimov, but it differs from them by the shape of gnathosoma, propodosoma and the course of apodemes, in addition to the structure and chaetotaxy of legs I-IV, especially solenidia on tarsi of both legs I and II, distinguished the new genus also from other described taxa.

\section{Egyptglyphus oconnori sp. nov. Description:}

(Deutonymph), Gnathosoma (Fig. 3). Infracapitulum of gnathosoma oblong; 30 (28-32) long, and 16 (14-18) wide; palps 19 (18-20) long, and 6 (5-7) wide, well- separated off, palps divided in the middle into two equal portions; apical palpal solenidia $(\omega) 56$ (55-57) setiform, stout; papal supracoxal setae (elcp) 17 (16-18), filiform; infracapitular setae $(m) 11(10-12)$.

Dorsum: (Figs. 1, 2). Body broadly ovoid, propodosoma and hysterosoma each covered with heavily punctuate sclerite. Idiosoma 413 (409-417) long, and 310 (305-315) wide. Propodosoma elongated medially, with lateral sides gradually narrowed to apex; posterior and lateral margins of propodosoma slightly concaved, however, remained triangular in outline; obtuse bell-like structure with narrowed apex located posterior to propodosomal apex. Propodosomal length: 63 (60-66) long, and 242 (239-245) wide. Internal vertical setae vi 23 (20-26), filiform, situated on propodosomal apex; external vertical setae ve 3 (2-4), filiform; internal scapular setae, sci 9 (8-10), and external scapular setae sce 15 (14-16), both filiform, internal scapular setae situated in the middle, anterior to external ones; supracoxal setae of legs I scx 6 (5-7), filiform. Dorsosejugal region well-developed, broad, ornamented with transversal lines on posterior portion and punctuate on anterior one. Hysterosoma with 11 pairs of simple, filiform setae, approximately at the same length, ranged for 10-12, except $h 2118$ (116-120). A pair of small ovoid cupules ia situated laterally between setae $c 2$ and $c p$.

Venter: (Fig. 4). Internal portions of coxal fields I, II, III punctuate, coxal fields IV completely punctuate. Apodemes thin, but well-developed. Anterior apodemes of coxal field I broad, fused medially forming sternum, the later short, ending free. Anterior and posterior apodemes of coxal fields II long, fused medially. Anterior and posterior apodemes of coxal fields III broad, fused with each other in the middle; well-developed lines, connected between middle of anterior apodemes III to posterior portions of coxal fields II. Anterior and posterior apodemes of coxal fields IV thin, but well-determined. Posterior sternal apodeme missing, however coxal fields II, III, IV closed, and coxal fields I open. Dorsal of hysterosomal sclerite separated from venter by a distinct suture on each side. Lateral and posterior margins of venter punctuate. Coxal fields I, III and IV with discs each $(1 a, 3 a$ and $4 a)$ slightly larger on coxal fields IV; genital setae $(g)$ filiform, situated laterally of genital opening, above 4a. Adhering plate (Fig. 5), approximately large 58 (54-62) long, and 84 (80-88) wide, entirely filling a space between legs IV, removed from the posterior margin of the body. Anterior suckers well-developed, comparatively large, and larger than lateral and posterior ones. Median suckers rounded, large; consisting of large sclerotized margins surrounded a pair of well-developed small disks. Adhering plate punctuated in internal areas between suckers.

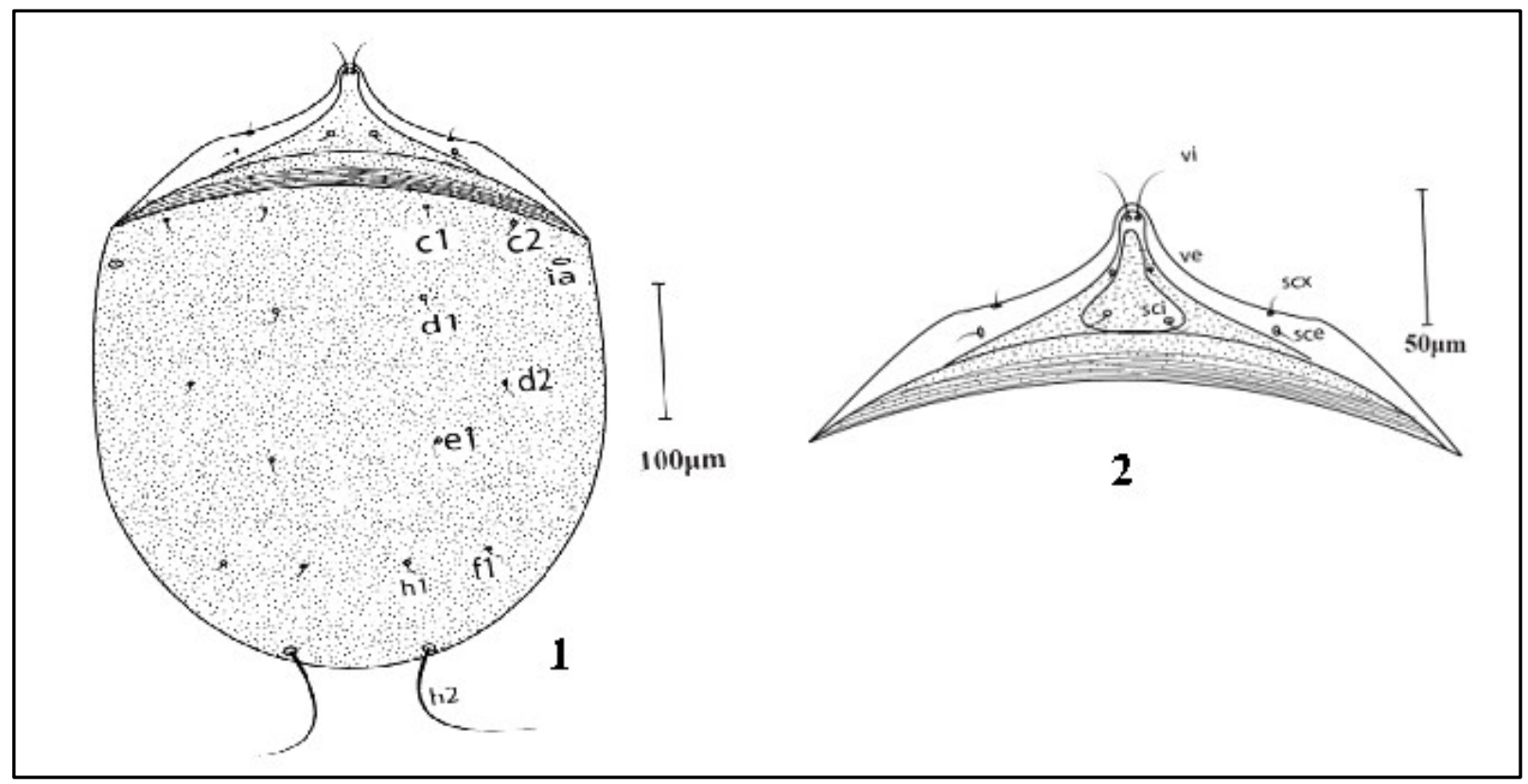

Figs. (1-2): Egyptglyphus oconnori sp. nov. (Deutonymph): 1. Dorsum of idiosoma; 2. Propodosoma. 

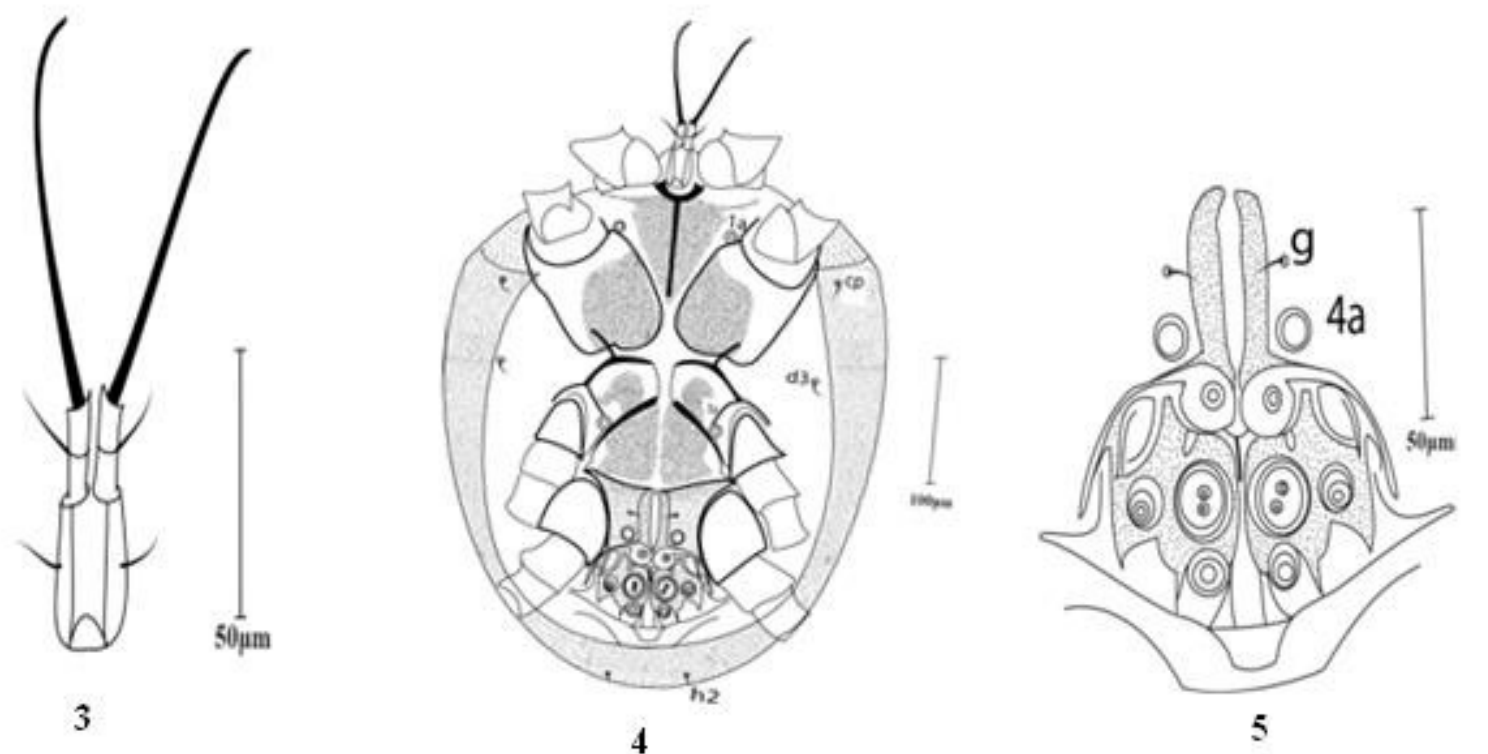

Figs. (3-5): Egyptglyphus oconnori sp. nov. (Deutonymph): 3. Gnathosoma; 4. Venter of idiosoma; 5. Adhering plate.

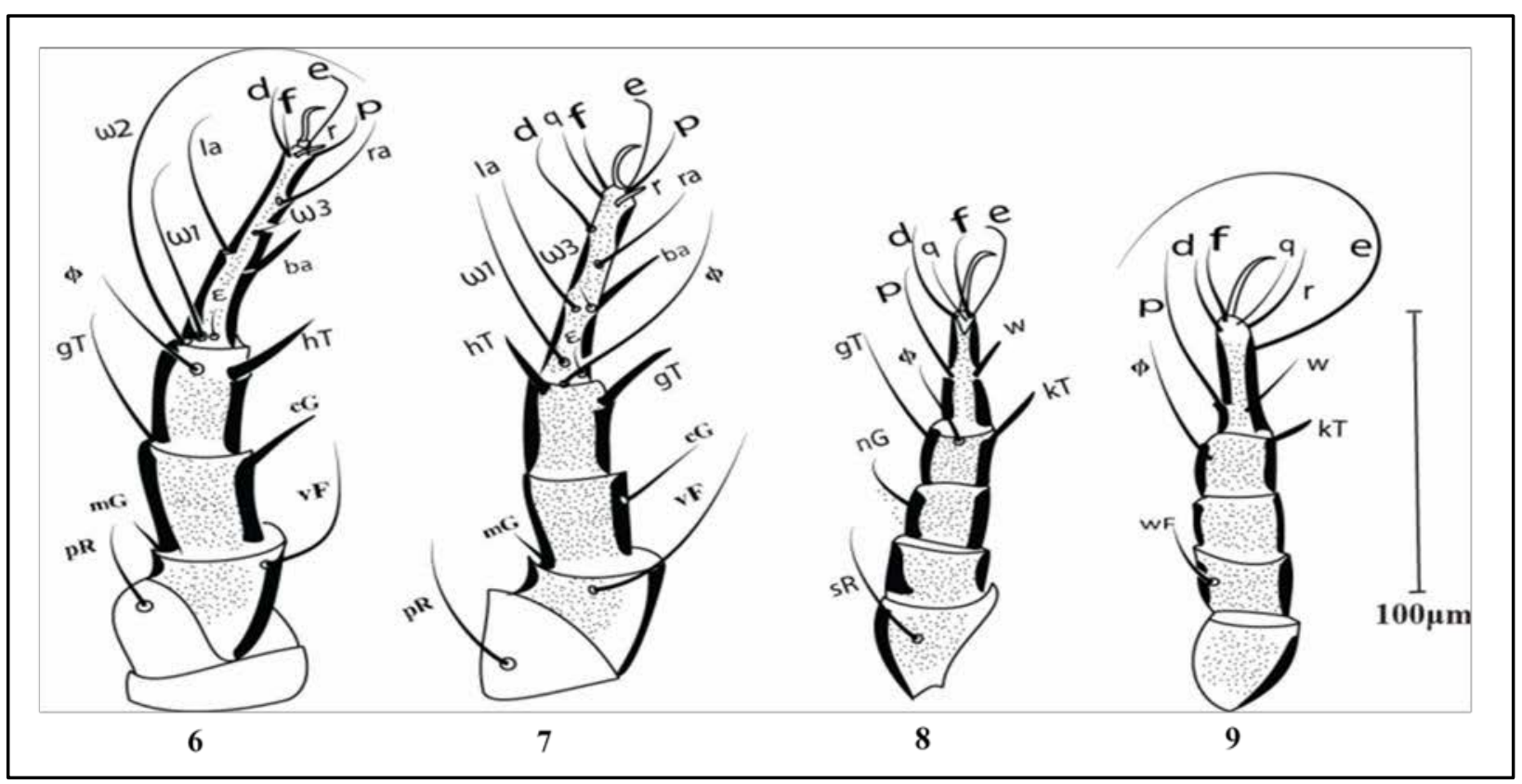

Figs. (6-9): Egyptglyphus oconnori sp. nov. (Deutonymph): 6. Leg I; 7. Leg II; 8. Leg III; 9. Leg IV.

Legs: (Figs. 6-9). Legs elongate segments free; all leg segments punctuate. Length of legs: I, 220; II, 182; III, 157; IV 77; tarsi; I, 88; II, 71; III, 43; IV 47. All legs with hooked empodial claws arising from tarsal apices, longer on legs IV. Trochanter I and II with setae $p R 32$ and 47 , respectively, setae $s R$ on legs III 52, filiform. Leg chaetotaxy-femora: 11-0-1; setae $v F$ I 60, II 107; $w F$ IV 32, filiform. Genua: 2-2-1-0; setae cG I 28, spiniform, II 33, filiform; setae $m G$ I 21 , II 17 ; setae $n G$ IV 17 , filiform. Tibiae: 2-2-2-1; setae $g T$ I 61, filiform, II 36, spine-like; III 44, filiform; $h T$ I 34, II 31, spine-like; $k T$ III 33, IV 11, both spine-like. All setae on tarsi IIV filiform, except $r$ on legs I, II, bacilliform; setae $b a$ and $w$ on legs III, spine-like. Length of tarsal setae: tarsus I, la 56, $d$ 26, f 20, e 34, r 9, p 17, ra 48, ba 31; tarsus II, la 54, $d$ 27, f 24, e 33, r 5, ra 45, q 34, ba 34; tarsus III, $p$ 62, $d$ 36, $q$ 29, $f 14$, e 27, $w$ 8.tarsus IV, $p$ 38, $f 18, q 27, r 30, w 31, e$ 100, $d$ 39. Tibiotarsal group of solenidia have been modified or replaced by a thin whip-like setae (short or long) instead of normal solenidia, especially solenidia $\omega$ and $\varphi$ on legs I and II. Solenidia on legs: I, $\omega 1$ 58, $\omega 2$ 142, $\omega 3$ 12, $\varepsilon$ 8 on tarsi, $\varphi 37$ on tibiae, $\sigma$ on genua absent; II, $\omega 1$ $51, \omega 38, \varepsilon 8, \varphi$ 63; $\omega 2$ located more basal and posterior to $\omega 1, \varepsilon$ situated adjacent to $\omega 1, \omega 3$ approximately in middle of tarsus I; on tarsi II, $\omega 1$ situated more lateral and anterior to $\varepsilon, \omega 3$ situated between setae $r a$ and $b a$, adjacent to setae $l a$; on leg III, $\varphi$ 26; on leg IV, $\varphi 48$ 
Type specimens: Holotype deutonymph and seven paratype deutonymphs collected from soil under pomegranate trees, Abou-Tig city $\left(27^{\circ} 02^{\prime} 38.3^{\prime \prime} \mathrm{N}\right.$, 3119'23.7" E), Assiut Governorate, Egypt, November 01, 2019, collected by A. S. Abdelgayed, are deposited in the Acari collection of Plant Protection Department, Faculty of Agriculture, Assiut University, Assiut governorate, Egypt.

Etymology: the name "oconnori" is given in honor of B. M. O'Connor, Professor of Acarology, University of Michigan, USA, for his contribution in such group of mites.

Remarks: According to the generic description, the new species cannot be similar to any known species. By the shape of its gnathosoma, propodosoma, the course of apodemes and the ornamentation on coxal fields I-IV, in addition to the structure and chaetotaxy of legs I-IV, especially solenidia on tarsi I and II, distinguished the new genus also from other described taxa.

\section{REFERENCES}

Diaz, A., Okabe, K.; Eckenrode, C. J.; Villani, M. G. and OC'onnor, B. M. 2000. Biology, ecology, and management of the bulb mites of the genus Rhizoglyphus (Acari: Acaridae). Exp. Appl. Acarol., 24: 85-113.

Eraky, S.A. 1993. Myianoetus lili sp. n. (Acari: Anoetidae) educed from manure, Assiut, Upper Egypt. Folia Entomol. Hung., 54: 47-49.

Eraky, S.A. 1994. Three new anoetid mites extracted from animal excrement and from garlic (Acari: Anoetidae). Folia Entomol. Hung., 55: 217-233.

Eraky, S.A. 1997. A key to new and old histiostomatid deutonymphs recorded in Assiut area with a description of two new species (Acari: Histiostmatidae). Assiut J. Agric. Sci., 28 (1): 99-116.

Eraky, S. A. 1998. Mahunkaglyphus solimani gen. and sp. n. and three new species Acari: Astigmata) described from termite nests, Western desert, Egypt. Folia ent. hung., 58: 241-250.

Eraky, S.A. 1999a. A new genus and three new species of mites (Acari: Acaridae) phoretic on termites infesting the camphor trees in Aswan, Egypt. Annls Hist. Nat. Mus. Natn. Hung., 91: 209-217.

Eraky, S. A. 1999b. Seven new species of mites (Acari: Acaridae) educed from different habitats in Upper Egypt. Assiut J. Agric. Sci., 30 (5): 65-80.

Eraky, S.A. 2000. Identification key for some
Acarididia mites (Acari: Astigmata) with descriptions of two new species. Assiut J. Agric. Sci., 31 (2): 341-371.

Eraky, S.A. and Osman, M.A. 2008. Caloglyphus manuri sp. n. (Acaridida: Acaridae) extracted from chicken manure, Mansoura, Egypt. Acarines, 2: 43-44.

Eraky, S.A. and Shoker, N. I. 1993. Mites extracted from uprooted banana suckers (Acari: Anoetidae).

Folia Entomol. Hung., 54:

51-56.

Fain, A. and Phillips, J. R. 1978. Astigmatic mites from nests of birds of prey in the U.S.R. 4 Description of the life-cycle of Acotyledon paradoxa Oudemans, 1903. Zool. Meded. Leiden, 53: 29-39.

Fan, Q.-H.and Zhang, Z.-Q 2004. Revision of Rhizoglyphus Claparédè (Acari: Acaridae) of Australasia and Oceania. Syst. Appl. Acarol. Soc., $374 \mathrm{pp}$.

Fan, Q.-H. and Zhang, Z.-Q. 2007. Tyrophagus (Acari: Astigmata: Acaridae). Manaaki Whenua Press, Lincoln, New Zeland, 56, 291 pp.

Fashing, N.J. 1974. A new subfamily of Acaridae, the Naiadacarinae, from water filled tree holes (Acarina: Acaridae). Acarologia, 16: 166-181.

Grandjean, F. 1939. La chaetotaxy des patteschez les Acaridiae. Bull. Soc. Zool, Fr., 64: 50-60.

Griffiths, D.A.; Atyeo, W. T.; Norton, R.A. and Lynch, C.A. 1990.The idiosomal chaetotaxy of astigmatid mites. J. Zool., 220: 1-32.

Kasuga, S. and Amano, H. 2006. Infestation of Tyrophagus similis Volgin (Acari: Acaridae) on spinach during the seed germination period. J. Acarol. Soc. Jap., 15: 69-73.

Klimov, P. B. 2000. A review of acarid mites of the tribe Caloglyphini (Acaridae: Acariformes) with description of a new genus and species from Siberia and Russian Far East. Vestnik Zoologii, 34: 27-35.

Klimov, P. B. and O'Connor, B.M. 2003. Phylogeny, historical ecology and systematic of some mushroom-associated mites of the genus Sancassania (Acari: Acaridae), with new generic synonymies. Invertebrate Systematics, 17: 469-514.

Klimov, P. B. and Tolstikov, A. V. 2011. Acaroid mites of Northern and Eastern Asia (Acari: Acaroidea). Acarina, 19: 252-264.

Rojas, E.W. and Klimov, P.B. 2007. Mites of the genus Rhizoglyphus (Acari: Acaridae) infesting cultivated bulbs in central and southern Chile, with taxonomic notes on Acarus hyacinthi Boisduval and Rhizoglyphus frickorum Nesbitt. Internat. J. Acarol., 33: 87-90. 